03

\title{
Невероятный эффект скорости подъема тепловой нагрузки на удельный тепловой поток при кипении некоторых наножидкостей
}

\author{
() Б.И. Бондаренко, В.Н. Морару ॠ, С.В. Сидоренко, Д.В. Комыш, \\ Н.Н. Гудков
}

Институт газа НАН Украины, Киев, Украина

^E-mail: vasily.moraru@gmail.com

Поступило в Редакцию 12 июля 2017 г.

Получены кривые кипения при различных скоростях подъема тепловой нагрузки (СПТН) для дистиллированной воды, водопроводной воды, а также для двух наножидкостей (НЖ) на основе природной смеси монтмориллонита и аттапульгита (AlSi-7) и диоксида титана (НЖ-8). Необычайно сильное влияние СПТН на тепловые параметры НЖ зафиксировано при кипении $\mathrm{AlSi}-7$ на основе смеси сильно анизометричных наночастиц алюмосиликатов различной морфологии, способных образовывать наноструктурированные ажурные „архитектуры“ на поверхности нагревателя. Предложено объяснение причин наблюдаемого эффекта. Полученные данные указывают на существование оптимальной СПТН, при которой в процессе кипения НЖ на поверхности нагрева возникает наиболее благоприятная для теплообмена структура осадка.

DOI: $10.21883 /$ PJTF.2018.11.46192.16965

В настоящее время феномен резкой интенсификации теплоотдачи и роста удельного теплового потока $\left(q_{s p}\right)$ при кипении наножидкостей (НЖ) по сравнению с наблюдаемыми для базовых жидкостей общепринято объяснять не только и не столько их повышенной теплопроводностью, сколько способностью НЖ изменять микрорельеф (шероховатость, пористость) и свойства поверхности нагрева вследствие отложения на ней структурированного слоя наночастиц (НЧ) [1-6]. Поскольку этот пористый слой начинает формироваться уже в докризисном режиме кипения $[4,5]$, представляет интерес выяснить, насколько сильно влияет на его структуру и тепловые свойства при 
кипении НЖ такой рабочий параметр, как скорость подъема тепловой нагрузки $(\mathrm{CПТН)}$. Цель исследования - выяснение влияния СПТН на максимально достижимый удельный тепловой поток $q_{\max }$ при кипении воды и различных НЖ.

Объектами исследования служили водные нанодисперсии природной смеси алюмосиликатов: монтмориллонита и аттапульгита (AlSi-7) с частицами чешуйчатой и игольчатообразной формы (Украина) [7], а также диоксида титана $\left(\mathrm{TiO}_{2}\right)$ преимущественно рутильной модификации. Нанофлюиды получали путем кратковременного $(5 \mathrm{~min})$ ультразвукового диспергирования на установке УЗДН-2Т соответствующих микропорошков в дистиллированной воде без добавок и с применением добавок диспергента - пирофосфата натрия $\mathrm{Na}_{4} \mathrm{P}_{2} \mathrm{O}_{7} \cdot 10 \mathrm{H}_{2} \mathrm{O}$ (0.01-0.05 wt.\%). Устойчивость исследуемых нанодисперсий, оцененная по величинам их $\xi$-потенциала и седиментационным методом, была вполне удовлетворительной для измерения тепловых параметров. Для сравнения испытаны дистиллированная вода (ДВ) и водопроводная вода $(\mathrm{BB})$ с удельной электропроводностью $1.0 \cdot 10^{-6}$ и $4.35 \cdot 10^{-4} \mathrm{~S} / \mathrm{cm}$ соответственно. Во всех нанодисперсиях содержание твердой фазы было значительно ниже точки перколяции, соответствующей резкому увеличению вязкости. Все наносуспензии имели полидисперсный характер распределения частиц по размерам (см. таблицу).

Дисперсный состав и $\xi$-потенциал НЖ определялись с помощью лазерного корреляционного спектрометра ZetaSizer NANO-ZS (Malvern Instrument, UK), а поверхностное натяжение - методом пластинки Вильгельми [8] (модифицированный тензиометр K6 KRÜSS GmbH, Germany). Некоторые физико-химические характеристики объектов исследования приведены в таблице.

Теплофизические исследования НЖ были выполнены на установке, работающей на постоянном токе и управляемой с помощью специально созданной компьютерной программы [4].

На рис. 1, $a$ приведены совмещенные зависимости максимально достижимого удельного теплового потока $q_{\max }$ от СПТН при кипении дистиллированной и водопроводной воды, а также наножидкостей НЖ-8 $\left(\mathrm{TiO}_{2}\right)$ и AlSi-7. Каждая экспериментальная точка на кривых соответствует отдельной кривой кипения, полученной при определенной СПТН. Заметим, что при всех СПТН величины $q_{\max }$ для наножидкостей значительно выше, чем для базовой жидкости (ДВ). 
Физико-химические характеристики и величины $q_{\max }$ и $\alpha_{\max }$ при кипении воды и некоторых водных наножидкостей

\begin{tabular}{c|c|c|c|c|c|c|c|c}
\hline $\begin{array}{c}\text { Изученная } \\
\text { жидкость }\end{array}$ & $\begin{array}{c}r_{a v}, \\
\mathrm{~nm}\end{array}$ & $\begin{array}{c}C, \\
\mathrm{wt} . \%\end{array}$ & $k$ & $\mathrm{pH}$ & $\begin{array}{c}\sigma, \\
\mathrm{mN} / \mathrm{m}\end{array}$ & $\begin{array}{c}\xi, \\
\mathrm{mV}\end{array}$ & $\begin{array}{c}q_{\max } \cdot 10^{-6}, \\
\mathrm{~W} / \mathrm{m}^{2}\end{array}$ & $\begin{array}{c}\alpha_{\max }, \\
\mathrm{W} /\left(\mathrm{m}^{2} \cdot \mathrm{K}\right)\end{array}$ \\
\hline ДВ & - & 0 & - & 5.8 & 72.8 & - & $0.7-1.2$ & 25000 \\
ВВ & - & 0 & - & 5.6 & 72.7 & - & 1.44 & 26500 \\
$\begin{array}{c}\text { ДВ + ТіО (рутил) } \\
\text { (НЖ-8) }\end{array}$ & $70-300$ & 0.8 & $1-5$ & 6.0 & 71.4 & -39.5 & 1.53 & 32000 \\
$\begin{array}{c}\text { ДВ + монтмориллонит } \\
\text { + аттапульгит } \\
\text { (AlSi-7) }\end{array}$ & $50-500$ & 0.45 & $200-500$ & 5.9 & 72.6 & -19.8 & 3.75 & 38000 \\
& & & & & & &
\end{tabular}

Пр и ме ч а и е. $r_{a v}-$ средний размер наночастиц, $C-$ концентрация наночастиц, $k=l / d-$ коэффициент анизометрии частиц, $\sigma$ - поверхностное натяжение НЖ при $20^{\circ} \mathrm{C}, \xi-$ электрокинетический потенциал, $q_{\max }-$ максимальный удельный тепловой поток, $\alpha_{\max }-$ максимальный коэффициент теплоотдачи. 

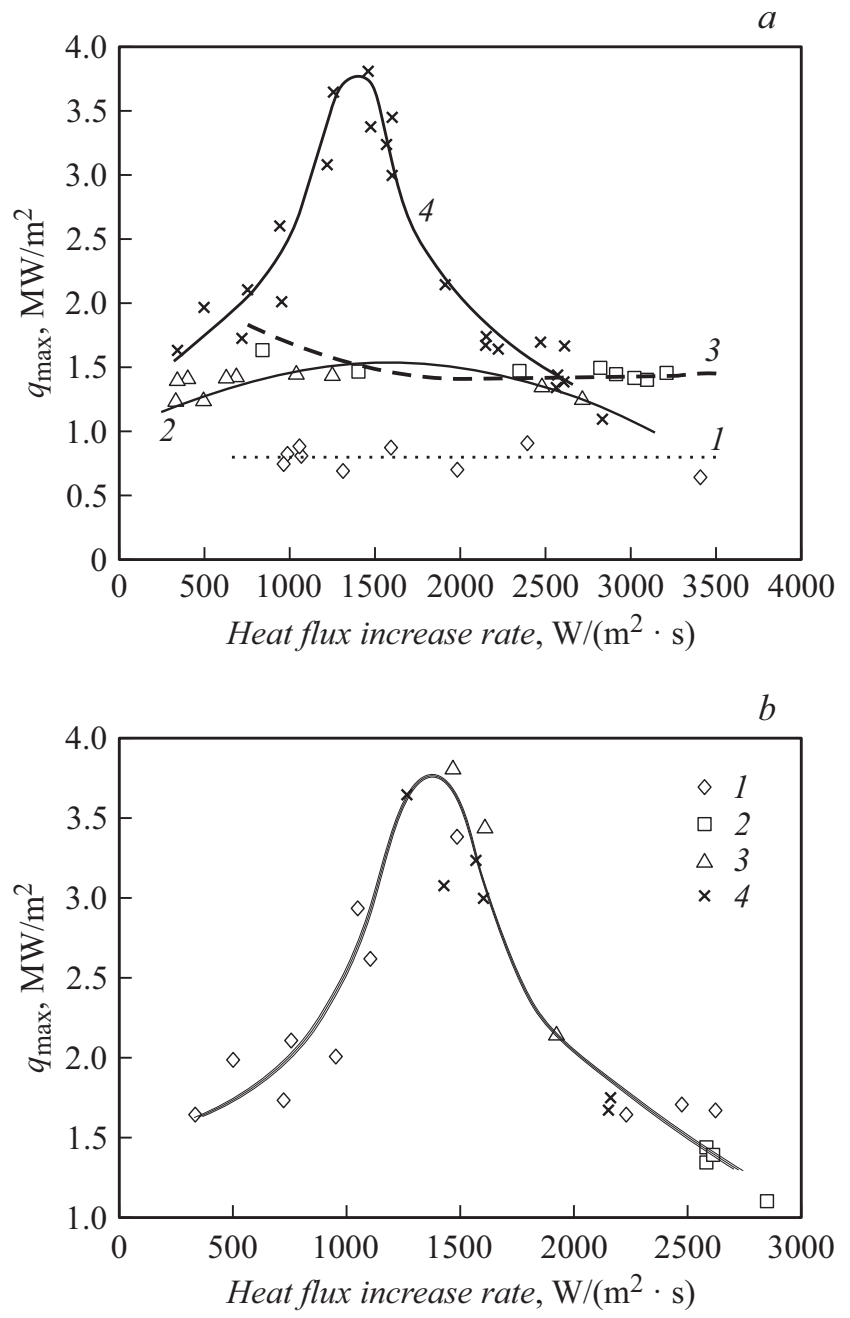

Рис. 1. $a-$ зависимости максимально достижимого удельного теплового потока при кипении ДВ (1), BВ (2) и наножидкостей НЖ-8 (3) и AlSi-7 (4) от СПТН; $b$ - зависимость максимально достижимого удельного теплового потока при кипении нанофлюида $\mathrm{AlSi}-7$, содержащего различные концентрации твердой фазы в пределах $0.1-1.0$ wt.\% $(1,4)$, диспергента $(0.01-0.05$ wt.\%) (2) и индифферентного электролита $(0.001-0.01 \mathrm{M} \mathrm{KCl})(3)$, от СПТН.

Письма в ЖТФ, 2018, том 44, вып. 11 
Как видно из рис. $1, a$ (кривая 4), при определенной средней величине СПТН, равной $1400 \mathrm{~W} /\left(\mathrm{m}^{2} \cdot \mathrm{s}\right)$, наблюдается поразительный скачок $q_{\max }$, причем только при кипении AlSi-7, полученной на основе смеси сильно анизометричных наночастиц алюмосиликатов различной морфологии. С дальнейшим увеличением СПТН эффект постепенно уменьшается и исчезает.

На кривой 3 (рис. 1,a) собраны данные для всех опытов по измерению $q_{\max }$ при кипении НЖ-8 независимо от концентрации и полиморфной модификации минерала (рутил или анатаз). Как видно, для НЖ-8 с изометричными частицами $\mathrm{TiO}_{2}$ эта зависимость почти линейная, т. е. нанодисперсия $\mathrm{TiO}_{2}$ не дает пиков на кривой зависимости $q_{\max }$ от СПТН в отличие от AlSi-7.

Кривая для водопроводной воды имеет небольшое пиковое значение $q_{\max }$ при постепенном повышении СПТН, что, вероятно, связано с различным характером отложения солей жесткости на поверхности нагревателя. Для дистиллированной воды, как и ожидалось, СПТН на значение $q_{\max }$ не влияет.

На рис. $1, b$ приведена зависимость $q_{\max }$ от величины СПТН при кипении AlSi-7 с различными концентрациями частиц, диспергента и индифферентного электролита. Точки 1 и 4 на рис. $1, b$ описывают поведение НЖ AlSi-7 для большинства проведенных опытов и различаются продолжительностью опыта и концентрацией твердой фазы в начальной суспензии.

Как видно, независимо от изменения концентрации частиц в НЖ и присутствия диспергента экстремальная зависимость $q_{\max }$ от СПТН для такого класса теплоносителей на основе смеси сильно анизометричных НЧ сохраняется, что очень важно для их практического применения.

Из рис. $1, b$ также следует, что существует такое оптимальное значение СПТН, при котором формируется наиболее эффективная по шероховатости и пористости текстура поверхности нагрева с точки зрения теплообмена. Благодаря проявлению высокой теплоотдачи такая „архитектура“ осадка эффективно защищает нагреватель от перегрева и пережога вплоть до максимальных тепловых нагрузок. Интересным является и тот факт, что введение индифферентного фонового электролита $(\mathrm{KCl})$ вплоть до концентрации $0.01 \mathrm{M}$ не влияет на динамику образования осадка в такой степени, чтобы изменить форму зависимости $q_{\max }$ от СПТН. Возникает вопрос: с чем же связано такое влияние СПТН на величину $q_{\max }$ ?

Письма в ЖТФ, 2018, том 44, вып. 11 
Из результатов экспериментов следует, что с увеличением СПТН формирование слоя НЧ на поверхности нагрева ускоряется, что влечет за собой рост $q_{s p}$. Последующее же уменьшение $q_{\max }$ с увеличением СПТН можно было бы объяснить чрезмерным утолщением или спеканием отложенного слоя. Но тогда неясно, почему в случае НЖ с изометричными частицами $\mathrm{TiO}_{2} q_{\max }$ не зависит от СПТН.

Вероятно, основная причина этого эффекта заключается в том, что при кипении НЖ с частицами различной формы с высокой анизометрией СПТН влияет на „архитектуру“ отложений на поверхности теплообмена. Уже тот факт, что данный эффект максимально проявляется при кипении AlSi-7, прямо свидетельствует о связи эффекта с формой и анизометрией частиц.

В самом деле, отложение слоя НЧ на поверхности нагревателя при кипении НЖ является прямым следствием пузырькового кипения и происходит в условиях одновременного воздействия нескольких видов полей: теплового (температурного), гидродинамического и электрического. На близких от поверхности нагрева расстояниях (порядка $50-100 \mathrm{~nm}$ ) необходимо учесть и влияние поля поверхностных сил на характер отложения частиц.

Очевидно, что в случае НЧ изометричной формы $\left(\mathrm{SiO}_{2}, \mathrm{TiO}_{2}\right.$, алмаз) независимо от направления и интенсивности упомянутых полей ориентация частиц практически не влияет на „архитектуру“ отложений на поверхности нагрева: возникший микрослой из НЧ более или менее плотный, однородный, с низкой пористостью и шероховатостью (рис. 2,a).

Иная картина наблюдается при кипении НЖ с частицами сильно анизометричной формы, ориентация которых чувствительна к величине и направлению полей. В зависимости от скорости нагрева и гидродинамики НЖ в приповерхностном слое нагревателя изменяется и взаимная ориентация НЧ, которые при адгезии (сцеплении) к поверхности нагрева образуют более беспорядочные ажурные „архитектуры“ с развитой пористостью и шероховатостью (рис. 2, b). По этой причине плотность центров парообразования и тепловые параметры при кипении нанофлюида AlSi-7 значительно выше, чем у НЖ-8.

Поскольку частицы НЖ всегда заряжены и окружены двойными электрическими слоями, на процесс их отложения одновременно накладывается и действие электрического поля нагревателя. При

Письма в ЖТФ, 2018, том 44, вып. 11 
Dispersion Deposit on the heater
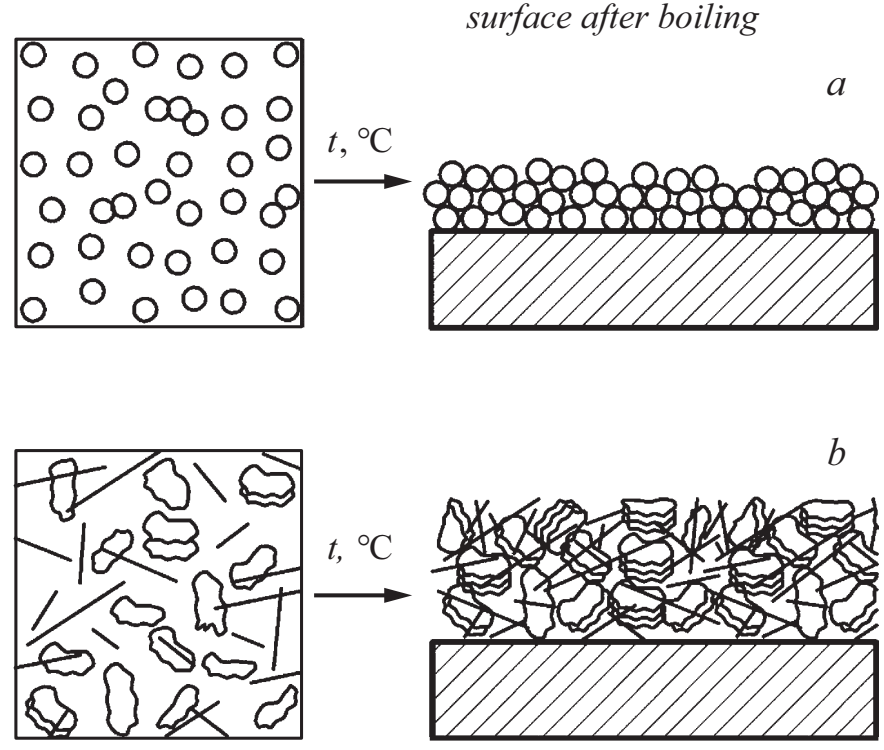

Рис. 2. Схематическое представление состояния наночастиц в наножидкости и в отложениях на поверхности нагревателя. $a-$ изометричные частицы (например, $\mathrm{SiO}_{2}$ или $\mathrm{TiO}_{2}$ ), $b$-анизометричные частицы природной смеси аттапульгита с монтмориллонитом.

определенной скорости нагрева и одновременном воздействии упомянутых выше полей возникает наиболее благоприятная взаимная ориентация анизометричных частиц различной формы и соответственно на поверхности нагрева формируется оптимальная для теплообмена „архитектура“, которая и обеспечивает интенсификацию кипения.

Важно учесть еще и специфику электрической топографии алюмосиликатных частиц, связанную с неоднородным распределением их поверхностного заряда. Дело в том, что вследствие своеобразной кристаллохимической структуры (слоистой и слоисто-ленточной), в основе которой лежат связанные между собой тетраэдрические кремнекислородные и октаэдрические алюмогидроксильные сетки, образу-

2 Письма в ЖТФ, 2018, том 44, вып. 11 


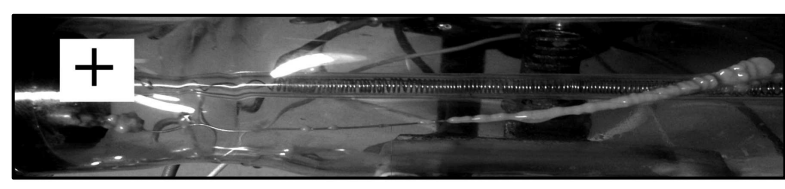

$a$

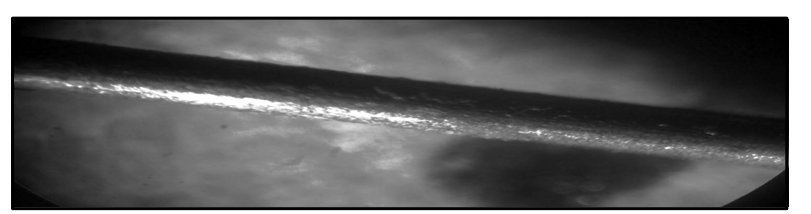

Рис. 3. Фотоизображения нагревателя с отложившимся гелеобразным осадком после 53 min кипения $0.45 \%$ HЖ AlSi-7 и пережога нагревателя при работе установки на постоянном $(a)$ и переменном $(b)$ токе.

ющие структурные слои, базальная поверхность AlSi-частиц заряжена отрицательно, тогда как их ребра и боковые грани - положительно $[7,9]$. По этой причине в таких водных дисперсиях легко возникают обратимые гелеобразные структуры типа карточного домика как следствие образования контактов типа плоскость-ребро-плоскость [9]. Это может быть еще одной причиной формирования ажурной пористой структуры отложений на поверхности теплообмена при кипении таких НЖ.

Наконец, в случае электрического нагрева необходимо учитывать влияние электрического поля поверхности нагревателя на заряженные частицы НЖ. Так, при кипении в установке, питаемой постоянным током, для всех алюмосиликатных НЖ без добавок диспергента наблюдается интенсивное отложение НЧ на медном положительном полюсе (аноде), а сформированный вокруг проволочного $\mathrm{Ni} / \mathrm{Cr}$-нагревателя осадок из НЧ имеет гелеобразную структуру и форму конуса, обращенного своим базисом к отрицательному полюсу (катоду) (рис. 3,a). Вероятно, это связано с тем, что часть отрицательно заряженных частиц алюмосиликатов разряжается и плотно осаждается на аноде, а другая часть, которая осаждается на поверхности нагревателя, испытывает все большее отталкивание, разрыхляющее действие и полное отторжение по мере приближения к отрицательному полюсу. На катоде и вблизи него либо осадок не образуется, либо электрическое поле

Письма в ЖТФ, 2018, том 44, вып. 11 
разрыхляет его до такой степени, что агрегаты частиц размываются под действием турбулентности, вызванной кипением [5]. В то же время при работе нагревателя на переменном токе отложения более или менее равномерны по своей толщине и распределены по всей длине $\mathrm{Ni} / \mathrm{Cr}$-проволоки, хотя и не образуют сплошного покрытия. При этом толщина осадка значительно меньше (рис. 3, $b$ ). Наблюдаемое различие в характере отложений на поверхности нагревателя при работе на постоянном и переменном токе объясняется наложением на процесс кипения НЖ явлений электрофореза и электрокоагуляции НЧ в результате прямого воздействия на суспензию электрического поля, которое более сильно в случае применения постоянного электрического тока.

Обнаруженный эффект СПТН имеет большое практическое значение для изготовления высокопроизводительных теплообменных изделий путем формирования нанорельефа на теплообменной поверхности изделия посредством осуществления на ней кипения наножидкости при оптимальной СПТН. Такой способ может быть использован при изготовлении изделий, содержащих теплообменные поверхности с микро- и нанорельефом, с целью интенсификации теплообмена [10].

Работа выполнена в рамках инновационного проекта ДАНІІ України № Д3/458-2013.

\section{Список литературы}

[1] Kim S.J., Bang I.C., Buongiorno J., Hu L.W. // Bull. Polish Acad. Sci. Techn. Sci. 2007. V. 55. N 2. P. 211-216.

[2] Pham Q.T., Kim T.I., Lee S.S., Chang S.H. // Appl. Thermal Eng. 2012. V. 35. P. $157-165$.

[3] Бондаренко Б.И., Морару В.Н., Сидоренко С.В., Комыш Д.В., Ховавко А.И. // Письма в ЖТФ. 2012. Т. 38. В. 18. С. 68-78.

[4] Bondarenko B.I., Moraru V.N., Ilienko B.K., Khovavko A.I., Komysh D.V., Panov E.M., Sydorenko S.V., Snigur O.V. // Int. J. Energy Clean Environment. 2013. V. 14. N 2-3. P. 151-168.

[5] Bondarenko B.I., Moraru V.N., Sydorenko S.V., Komysh D.V., Khovavko A.I. // Nanosci. Nanoeng. 2016. V. 4. N 1. P. 12-21. doi: 10.13189/nn.2016.040102

[6] Бондаренко Б.И., Морару В.Н., Сидоренко С.В., Комыш Д.В. // Письма в ЖТФ. 2016. Т. 42. В. 13. С. $32-43$.

2* Письма в ЖТФ, 2018, том 44, вып. 11 
[7] Тарасевич Ю.И. Строение и химия поверхности слоистых силикатов. Киев: Наук. думка, 1988. 248 c.

[8] Адамсон А. Физическая химия поверхностей. М.: Мир, 1979. 568 с.

[9] Van Olphen H. An introduction to clay colloid chemistry. N.Y.: John Wiley \& Sons, 1977. $318 \mathrm{p}$.

[10] Kuzma-Kichta Ju.A., Lavrikov A.V., Parshin N.Ja., Turchin V.N., Ignat'ev D.N., Shtefanov Ju.P. Patent RU 2433949. Int.Cl. B82B 3/00 (2006.01), B82Y 40/00 (2011.01). Method to form nanorelief on heat-exchange surfaces of products. Publ. 20.11.2011. Bull. 32. 